\title{
Factors Driving Embodied Carbon Emissions from China-US Trade for 1992-2012: A Structural Decomposition Analysis
}

\author{
Junping $\mathrm{Ji}^{1,2}$, Can Zhang ${ }^{1}$ and Xiaoming $\mathrm{Ma}^{1,2, \mathrm{a}}$ \\ ${ }^{1}$ Key Laboratory for Urban Habitat Environmental Science and Technology, School of Environment \\ and Energy, Peking University Shenzhen Graduate School, Shenzhen, Guangdong, China \\ ${ }^{2}$ College of Environmental Sciences and Engineering, Peking University, Beijing, China \\ aCorresponding author: xmma@pku.edu.cn
}

\begin{abstract}
Keywords: bilateral China-US trade; environmental input-output analysis; structural decomposition analysis (SDA); embodied carbon emissions

Abstract. China and the United States are the top two carbon emitters worldwide, and bilateral trade between the two countries plays a vital role in driving their emissions. Defining the key drivers and sectors for the emissions embodied in China-US trade will provide opportunities for identifying avenues for reducing overall carbon emissions. In this study, we employed structural decomposition analysis to investigate the driving factors and their mechanisms for carbon emission growth embodied in China-US trade from 1992 to 2012. The results are as follows. First, emissions embodied in bilateral trade increased by $444.8 \%$ (229.69 $\mathrm{Mt} \mathrm{CO}_{2}$ ) from 1992 to 2012, although emissions decreased slightly between 2007 and 2012. Carbon intensity and trade volume were the largest negative and positive driving factors, accounting for $216.3 \%$ and $-150.1 \%$ of the total emissions change, respectively. Second, carbon-intensive products dominated China-US trade during this time period. Products were derived from sectors such as electronic and communication equipment manufacturing, chemical industry, electric machinery and equipment manufacturing, and metal products. This study shows that improving energy efficiency and controlling the trade volume of carbon-intensive products are two effective measures for mitigating emissions embodied in China-US trade.
\end{abstract}

\section{Introduction}

As the top two worldwide carbon emitters, China and the United States (US) emitted $30 \%$ and $15 \%$ of global carbon emissions in 2013, respectively [1]. To combat climate change, the two countries announced ambitious emission reduction goals in the China-US Joint Announcement on Climate Change in 2014. International trade plays a vital role in driving emissions changes from both countries [2,3]. Li et al. [4] analyzed carbon emissions embodied in China's trade in 2004 and revealed that 1/4 of total emissions from exports were caused by those to the US. As important trade partners, the US is China's largest export market, and China is the third largest importer of US products [5]. Therefore, it is essential to understand the key drivers behind carbon emissions embodied in China-US trade to identify opportunities for reducing overall carbon emissions from China and the US.

Input-output analysis is widely used in studying carbon emissions embodied in China's trade [6]. Shui and Harriss [7] pointed out that China-US trade decreased carbon emissions in the US and increased carbon emissions in China. This difference is caused by China consuming more manufacturing energy and produced more carbon dioxide than the US with the same output [8]. Structural decomposition analysis (SDA), based on input-output analysis, is often applied for analyzing the causes of changing carbon emissions. Peters et al. [9] found that infrastructure and urban residential consumption drove China's increasing carbon emissions for 1992-2002, while technological progress drove most of the primary decreases. Minx et al. [10] argued that China's economic structure emerged as the third key driver of increasing carbon emissions for 2002-2007. Du et al. [2] showed that the largest driver of emissions embodied in China's trade was trade volume, followed by the input-output structure.

Based on the newly released 2012 Input-Output Tables of China and World Input-Output Tables, 
we use SDA to investigate the driving factors and their mechanisms for carbon emission growth embodied in China-US trade from 1992 to 2012.

\section{Method and Data}

Structural Decomposition Analysis. Carbon emissions embodied in trade can be expressed as

$$
\boldsymbol{f}=\boldsymbol{F}(\boldsymbol{I}-\boldsymbol{A})^{-1} \boldsymbol{y}_{s} y_{v},
$$

where $\boldsymbol{f}$ refers to embodied carbon emissions in China-US trade; $\boldsymbol{F}$ is a vector of sectoral carbon intensity; $\boldsymbol{I}$ is a unit matrix; $\boldsymbol{A}$ is a matrix of direct production coefficients; $\boldsymbol{y}_{\boldsymbol{s}}$ is a vector of trade structure in China-US trade; and $y_{v}$ is trade volume. Therefore, the change in $f$ can be calculated from

$$
\Delta \boldsymbol{f}=\Delta \boldsymbol{F L} \boldsymbol{y}_{s} y_{v}+\boldsymbol{F} \Delta \boldsymbol{L} \boldsymbol{y}_{s} y_{v}+\boldsymbol{F} \boldsymbol{L} \Delta \boldsymbol{y}_{s} y_{v}+\boldsymbol{F} \boldsymbol{L} \boldsymbol{y}_{s} \Delta y_{v},
$$

where the first term on the right side of the equation represents emission changes induced by changes in sectoral carbon intensities, in which we use $\boldsymbol{L}$ to denote $(\boldsymbol{I}-\boldsymbol{A})^{-1}$; the second term indicates the changes in input-output structure; the third term incorporates the changes in trade structure; and the fourth term represents the changes in trade volume. We use a weighted average method to average all decomposition equivalents [11].

Data. The input-output tables of China for 1992, 1997 and 2002 are from Liu and Peng [12], and we constructed tables for 2007 and 2012 as the same authors did. The input-output tables of the US are from the World Input-Output Database (WIOD). All tables are in 2000 prices and have 23 sectors (refer to Table 1). We followed Peters et al. [13] to calculate China's carbon emissions from energy activities and industrial processes using the China Energy Statistical Yearbook and China Industrial Economy Statistical Yearbook as main sources. The US carbon emissions are obtained from the World Input-Output Database (WIOD). Bilateral trade data between China and the US are available from the United Nations Commodity Trade Statistics Database (COMTRADE). However, the data are classified in HS Code, which are different from the sectors in the input-output tables. Therefore, we regrouped the COMTRADE data into the 23 input-output table sectors, as in Sheng Bin [14].

\begin{tabular}{|c|c|c|c|}
\hline No. & Sector & No. & Sector \\
\hline 1 & Agriculture & 13 & Chemical industry \\
\hline 2 & Coal mining and dressing & 14 & Nonmetal mineral products \\
\hline 3 & Petroleum and natural gas extraction & 15 & Smelting and pressing of metals \\
\hline 4 & Metals mining and dressing & 16 & Metal products \\
\hline 5 & Nonmetal minerals mining and dressing & 17 & $\begin{array}{l}\text { Industrial machinery and equipment } \\
\text { manufacturing }\end{array}$ \\
\hline 6 & $\begin{array}{l}\text { Other ores mining and support activities } \\
\text { for mining }\end{array}$ & 18 & $\begin{array}{l}\text { Transportation machinery and equipment } \\
\text { manufacturing }\end{array}$ \\
\hline 7 & Food, beverage, and tobacco processing & 19 & Electric machinery and equipment manufacturing \\
\hline 8 & Textile industry & 20 & $\begin{array}{l}\text { Electronic and communication equipment } \\
\text { manufacturing }\end{array}$ \\
\hline 9 & $\begin{array}{l}\text { Garments, leather, down, and other fiber } \\
\text { products }\end{array}$ & 21 & $\begin{array}{l}\text { Instruments, meters, and other measuring } \\
\text { equipment manufacturing }\end{array}$ \\
\hline 10 & $\begin{array}{l}\text { Timber processing and furniture } \\
\text { manufacturing }\end{array}$ & 22 & Other manufacturing products \\
\hline 11 & $\begin{array}{l}\text { Papermaking, printing, and cultural, } \\
\text { educational articles }\end{array}$ & 23 & Other sectors \\
\hline 12 & $\begin{array}{l}\text { Petroleum processing, coking, and nuclear } \\
\text { fuel processing }\end{array}$ & & \\
\hline
\end{tabular}

Table 1. Sector classification 


\section{Results and Discussion}

Primary Factors Driving Carbon Emissions Embodied in China-US trade. As seen in Fig. 1, emissions embodied in the bilateral trade increased by 444.8\% (229.69 $\left.\mathrm{Mt} \mathrm{CO}_{2}\right)$ from 1992 to 2012. Trade volume was the main growth factor, accounting for $216.3 \%$ of the total emission change. Carbon intensity was the main factor in decreasing emissions, explaining $-150.1 \%$ of emission growth. During the period 2002-2007, input-output structure contributed an $80.37 \mathrm{Mt} \mathrm{CO}_{2}$ change, emerging as the second largest factor increasing carbon emissions in China-US trade. This was likely due to the Chinese product supply chain turning to carbon-intensive activities in that period [10].

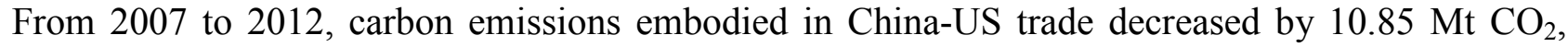
where the contribution from carbon intensity was $283.7 \%$, followed by input-output structure at $79.2 \%$. Trade volume was still the main factor controlling growth, but its contribution dropped to $21.44 \mathrm{Mt} \mathrm{CO}_{2}$, decreasing $87.3 \%$ compared with the previous period. This significant change indicates that China made a great progress in improving energy efficiency and decarbonizing the production structure after implementation of its 11th and 12th Five Year Plan.

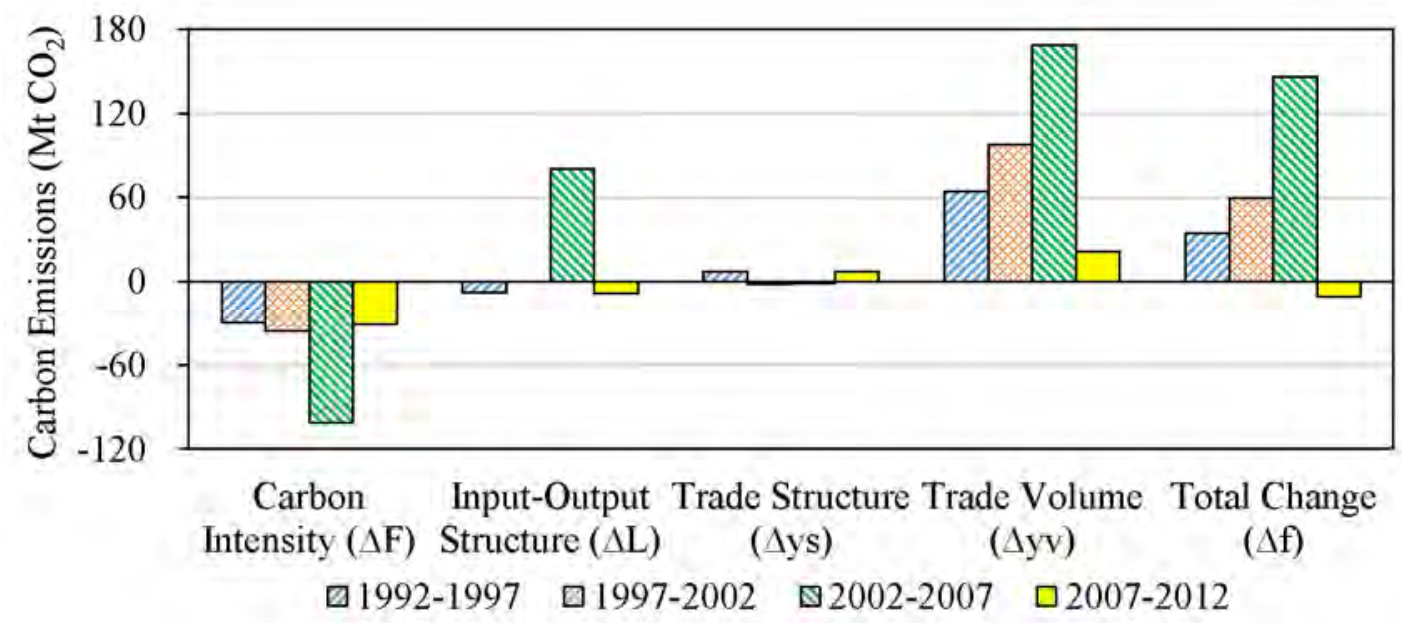

Figure 1. Changes in carbon emissions from China-US Trade based on driving factors for 1992-2012

Carbon Intensity Effects. Carbon intensities declined in most sectors in all periods, especially in 2002-2007 (refer to Fig. 2). Improvements in energy and production efficiency in the following five sectors contributed to a $50 \%$ reduction in emissions: electronic and communication equipment manufacturing (sector 20), chemical industry (sector 13), electric machinery and equipment manufacturing (sector 19), metal products (sector 16), and industrial machinery and equipment manufacturing (sector 17). For the 10th and 11th Five-Year Plan periods, the Chinese government invested heavily in energy efficiency and renewable energy, and implemented a series of energy conservation policies, and effectively reducing carbon intensity.

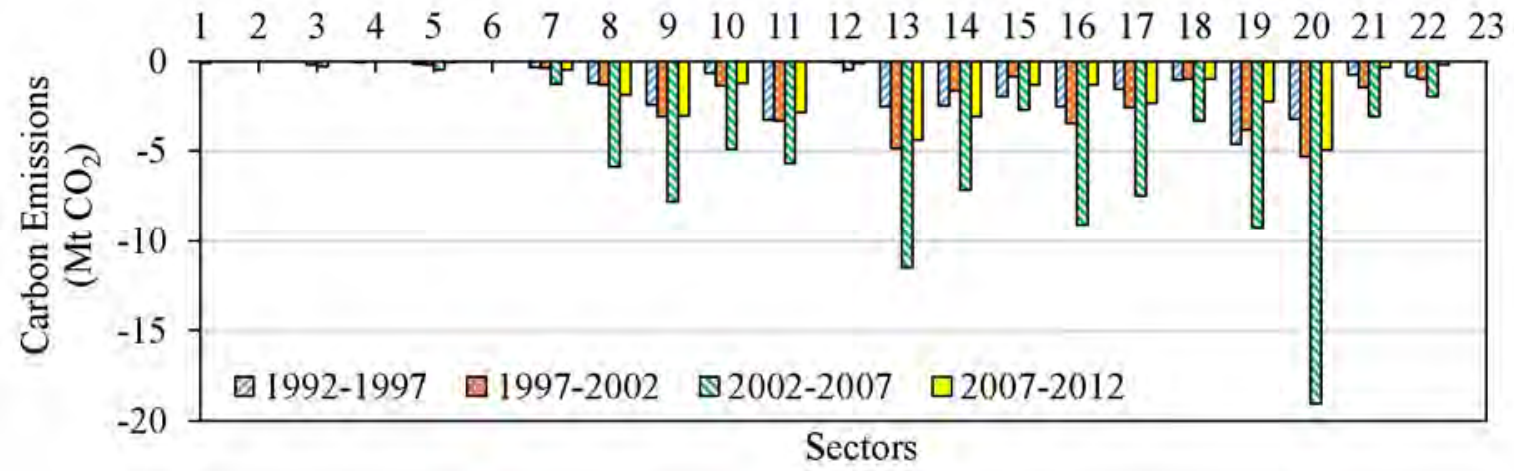

Figure 2. Carbon emission changes caused by sectoral carbon intensity changes for 1992-2012

Input-Output Structure Effects. As shown in Fig. 3, the effects of input-output structure on carbon emissions generally led to decreases for 1992-2002 and 2007-2012, but increases for 
2002-2007. This implies that some sectors produced more carbon-intensive products in their manufacturing processes in 2002-2007 than that in other periods, such as electronic and

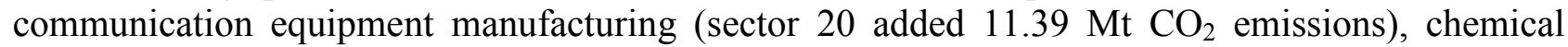
industry (sector 13 added $9.30 \mathrm{MtCO}_{2}$ ), garments, leather, down, and other fiber products (sector 9 added $8.08 \mathrm{Mt} \mathrm{CO}_{2}$ ), and industrial machinery and equipment manufacturing (sector 17 added 6.76 $\mathrm{Mt} \mathrm{CO}_{2}$ ). However, China subsequently placed more emphasis on low carbon production in 2007-2012, and the supply chain for these sectors became less carbon-intensive.

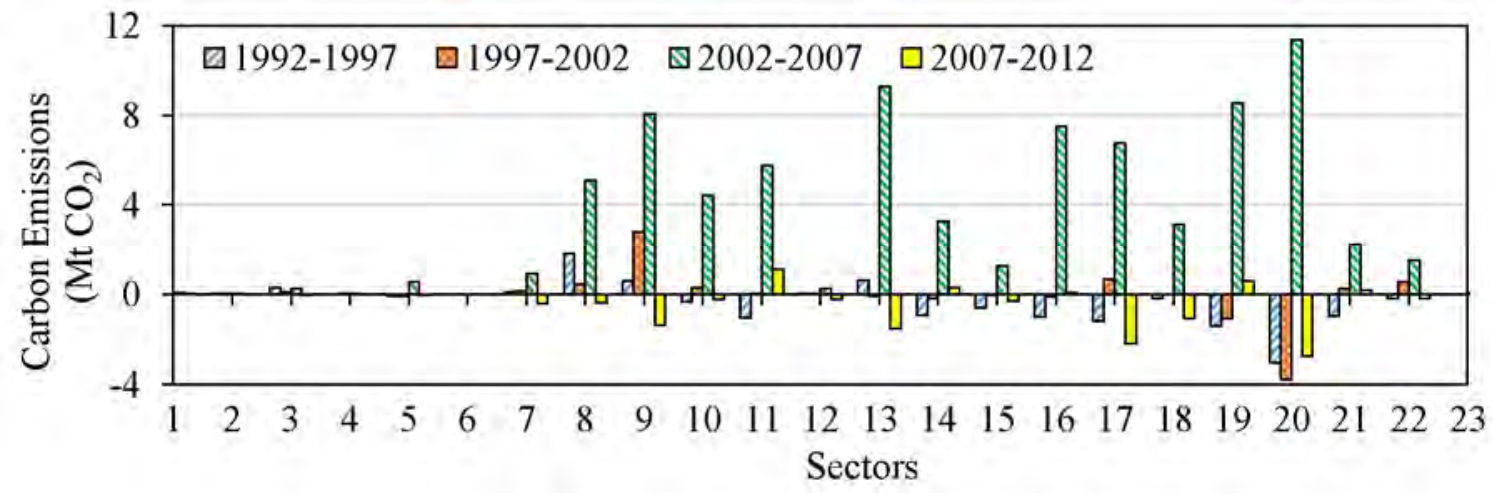

Figure 3. Carbon emission changes caused by input-output structure changes for 1992-2012

Trade Volume Effects. As a global factory, China produces a broad spectrum of products for worldwide consumption. Trade volume growth between China and the US drove embodied carbon emission growth in most sectors (refer to Fig. 4). The emissions changes for the top six sectors accounted for approximately $60 \%$ of emissions from trade volume effects, including electronic and communication equipment manufacturing (sector 20), chemical industry (sector 13), electric machinery and equipment manufacturing (sector 19), metal products (sector 16), industrial machinery and equipment manufacturing (sector 17) and garments, leather, down, and other fiber products (sector 9). The production of electronic and communication equipment (sector 20) has been the major emission contributor since 1997. Its share in trade volume effects increased from $8.0 \%$ in $1997-2002$ to $18.8 \%$ in $2007-2012$.

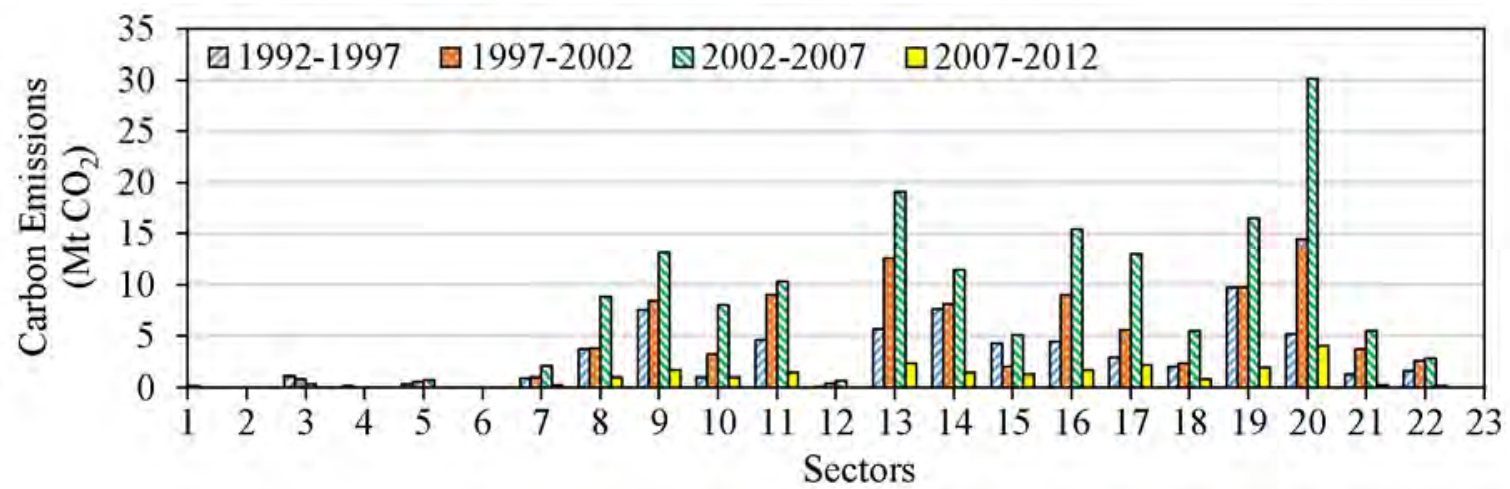

Figure 4. Carbon emission changes caused by trade volume changes for 1992-2012

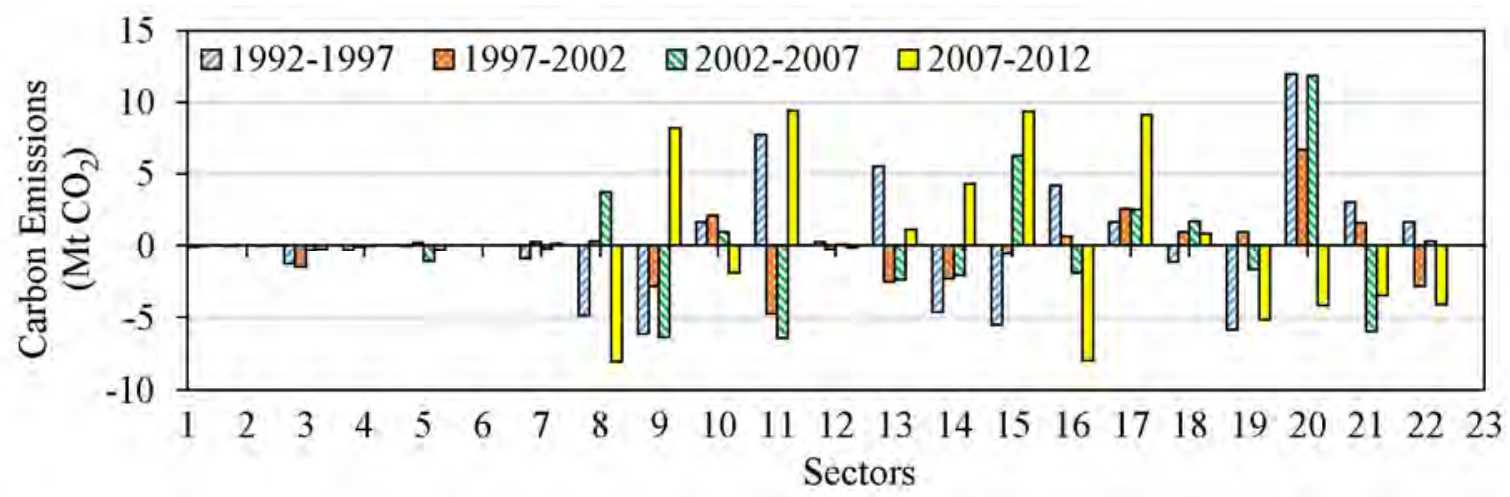

Figure 5. Carbon emission changes caused by trade structure changes for 1992-2012 
Trade Structure Effects. Although the overall effects of trade structure on carbon emissions is small compared with other factors (refer to Fig. 1), the sectoral emissions exhibited different characteristics (refer to Fig. 5). From 1992 to 2012, the expanding shares of industrial machinery and equipment manufacturing (sector 17) and electronic and communication equipment manufacturing (sector 20) in China-US trade made these sectors the top two contributors to emission growth. The garments, leather, down, and other fiber products (sector 9), nonmetal mineral products (sector 14), and electric machinery and equipment manufacturing (sector 19) were the three biggest contributors to offsetting emissions, because the shares of these sectors in China-US trade dropped from $15.0 \%$, $15.4 \%$, and $20.9 \%$ in 1999 to $8.9 \%, 7.1 \%$, and $8.4 \%$, respectively.

\section{Conclusions}

Carbon emissions embodied in China-US trade increased by 229.69 Mt CO 2 between 1992 and 2012. Carbon intensity and trade volume were respectively the largest negative and positive driving factors. The embodied emissions for 2007-2012 decreased by $10.85 \mathrm{Mt} \mathrm{CO}_{2}$ due to the reduction in trade volume in this period. The sectors with largest impact on embodied emissions were the chemical industry (sector 13), metal products (sector 16), industrial machinery and equipment manufacturing (sector 17), electric machinery and equipment manufacturing (sector 19), and electronic and communication equipment manufacturing (sector 20). Carbon-intensive products dominated China-US trade for 1992-2012, resulting in the growth of embodied emissions. This study shows that, for these key sectors, improving energy efficiency and controlling the trade volume of carbon-intensive products are two effective measures for mitigating emissions from China-US trade.

\section{References}

[1] CAIT Climate Data Explorer on http://cait2.wri.org

[2] H. Du, J. Guo, G. Mao, A.M. Smith, X. Wang, Y. Wang: Energy Policy Vol. 39 (2011), p. 5980-5987

[3] S.J. Davis, K. Caldeira: Proc. Natl. Acad. Sci. Vol. 107 (2010), p. 5687-5692

[4] Y. Li, J. Fu, Z. Ma, B. Yang: Chinese Geogr. Sci. Vol 24 (2014), p. 220-230

[5] R. Yang, R. Long, T. Yue, H. Shi: Energy Policy Vol. 72 (2014), p. 110-119

[6] Z. Zhang, Y. Zhao, B. Su, Y. Zhang, S. Wang, Y. Liu, H. Li: Renew. Sustain. Energy Rev. Vol. 68 (2017), p. 492-510

[7] B. Shui, R.C. Harriss: Energy Policy Vol. 34 (2006), p. 4063-4068

[8] M. Xu, E. Williams, B. Allenby: Environ. Sci. Technol. Vol. 44 (2010), p. 567-573

[9] G.P. Peters, C.L. Weber, D. Guan, K. Hubacek: Environ. Sci. Technol. Vol. 41 (2007), p. 5939-5944

[10]J.C. Minx, G. Baiocchi, G.P. Peters, C.L. Weber, D. Guan, K. Hubacek: Environ. Sci. Technol. Vol. 45 (2011), p. 9144-9153

[11]J. Li: J. Syst. Sci. Complex. Vol. 18 (2005), p. 210-218

[12]Q. Liu, Z. Peng: China's Input-Output Tables in Constant Prices 1992-2005 (China Statistics Press, Beijing, China 2010).

[13]G. Peters, C. Weber, J. Liu: Construction of Chinese Energy and Emissions Inventory (Norwegian University of Science and Technology, Trondheim, Norway 2007).

[14]B. Sheng: Political Economy of China's Trade Policy (Shanghai People's Publishing House, Shanghai, China 2002). 